\title{
An Innovative Design and Evaluation of a Stratified Hot Water Storage System
}

\author{
The Water Snake
}

\author{
Simon Fanshawe ${ }^{1}$, Amin Al-Habaibeh ${ }^{2}$ and Bubaker Shakmak ${ }^{2}$ \\ ${ }^{1}$ Gannet Limited, 78 Burton Road, Carlton Nottingham, NG4 3DH, UK \\ simon@gannet.co.uk \\ ${ }^{2}$ Innovative and Sustainable Built Environment Technologies (iSBET), \\ School of Architecture, Design and the Built Environment, Nottingham Trent University, \\ NG1 4BU, UK \\ Amin.Al-Habaibeh@ntu.ac.uk; bubaker.shakmak2008@my.ntu.ac.uk
}

\begin{abstract}
The increase in energy prices and the demand to reduce carbon emission is attracting the attention to the implementation of diverse heating technologies such as heat pumps, solar energy, gas boilers, CHP and electric heaters. Heating applications for integrated technologies include district heating, domestic small scale applications and commercial large scale buildings. Thermal storage is likely to become key to energy efficient heating. A stratified hot water tank will play an important role in the integration of several heating technologies that operate efficiently at different level of temperatures with reduced implementation cost. This paper describes the concept and the assessment of the 'Water Snake', a novel low cost concept of a stratified hot water tank. The results show that the new concept could provide efficient stratification at a very low cost using this invention.
\end{abstract}

Keywords: Sustainability, Stratification; Water Snake; Hot water storage, Heat pumps, District heating.

\section{INTRODUCTION}

Currently most space heating is powered by the direct combustion of fuels. Condensing gas boilers can deliver around $90 \%$ of the calorific value of the gas into a property. The technology is well developed and, with a theoretical limit of $100 \%$ only tiny improvements can be expected with tweaks to the design. A modern gas turbine can convert the heat to electricity and deliver $50 \%$ of the calorific value to the end user. With existing technologies heat pumps can realistically pump an additional $150 \%$ from an external source more than doubling the overall efficiency for space heating.

A much discussed and unsolved problem in electricity generation is the storage of electricity. The cost of storing enough electric energy in batteries to even out peaks in demand is prohibitive and likely to remain so for the near future. Other strategies such as moving water between high and low level lakes are costly and contribute little. As inputs from nuclear power and "renewables" replace fossil fuels, the need to match the demand to the supply will become ever more important. Switching off commercial loads in peak times is already common practice. Where electricity is used for heating, it is much cheaper to convert the power to heat and to store the heat. In the near future, sophisticated demand management of domestic loads will become inevitable, and substantial heat storage may even become a requirement for new domestic heating systems. In this case a "thermal store" is a store for hot water. In the older conventional systems, these were heated by a boiler through a coil and used to store domestic hot water. In more modern systems, the water in the vessel is heated directly by the heat source(s) and domestic hot water is heated by passing it through a coil inside the thermal storage. This avoids the legionella risk and allows the space heating to use the same reservoir. "Stratification" is the intention to heat two or more horizontal layers to different temperatures. Typically, the lower $60 \%$ of a thermal store is heated to an appropriate temperature for space heating with the top $40 \%$ being at a temperature high enough for the hot water preparation. The less mixing there is between fluid at different temperatures, the more efficient the stratification is.

The market for thermal storage systems is already well established and effective stratification is becoming an increasingly important feature both for environmental and commercial reasons. Many design for improving stratification have been developed and commercialised, and many references available in literature to address this field of research [1-4]. These primarily consist of fixed baffles, separation plates and flow guides. 
A key problem faced by the strategists planning future electricity generation is that of demand management. Typically demand variation in the UK is 2:1 over a 24 hour period. Wind and solar generation make the problem worse because the supply is unpredictable and often not available when it is most needed. If more electricity for heating was supplied on an as needed basis this problem would get worse, especially on cold winter evenings. It is very difficult and expensive to store electric energy. This means that the generation capacity in the country has to exceed the worst case demand for power. On the grid there are small power stations, such as CHPs, there are purely to operate in at times of unexpectedly high demand in most cases. Storing electricity in batteries is not likely to be cost effective in the foreseeable future. The generation industry is increasingly looking at demand management to solve the problem. This means that storing heat in homes is likely to become a requirement for electric heating systems using heat pumps. The heat pump only runs when there is capacity available, the stored heat keeps the house warm during peak periods.

Night storage heaters are already widely used for space heating. Adding a thermal storage system to an efficient heat pump offers the possibility of a heating system using conventional radiators with the same demand pattern but with running costs and energy usage around a third of that of storage heaters. Thermal storage systems are already widely used with solar thermal systems so that the heat can be used after sunset. They are also used for heat pumps and boilers. There is an increasing market for large stratified thermal storage systems as they allow inputs from different heat sources to be combined and used for heating and hot water inside the property.

When fluid enters a thermal store, it needs travel to the layer at the same temperature whilst minimising the mixing of fluid different temperatures. There are many innovations, designs and patents specifically aimed at minimising this mixing. The following describes a radically new idea for doing the same.

\section{THE WATER SNAKE CONCEPT}

Stratification is another word for layering. There are many innovations, designs and patents specifically aimed at minimising mixing and turbulence for water entering a stratified thermal store. The Water Snake is a radically new method for doing the same. It is a highly flexible thin walled tube which is fixed and sealed to the feed into the vessel. The open end is free to float within the vessel such that it will rise or drop to a position of neutral buoyancy. Thus, when the fluid moving down the snake mixes with the fluid in the body of the vessel the temperatures will be the same, Fig. 1 presents a schematic diagram of the Water Snake concept.

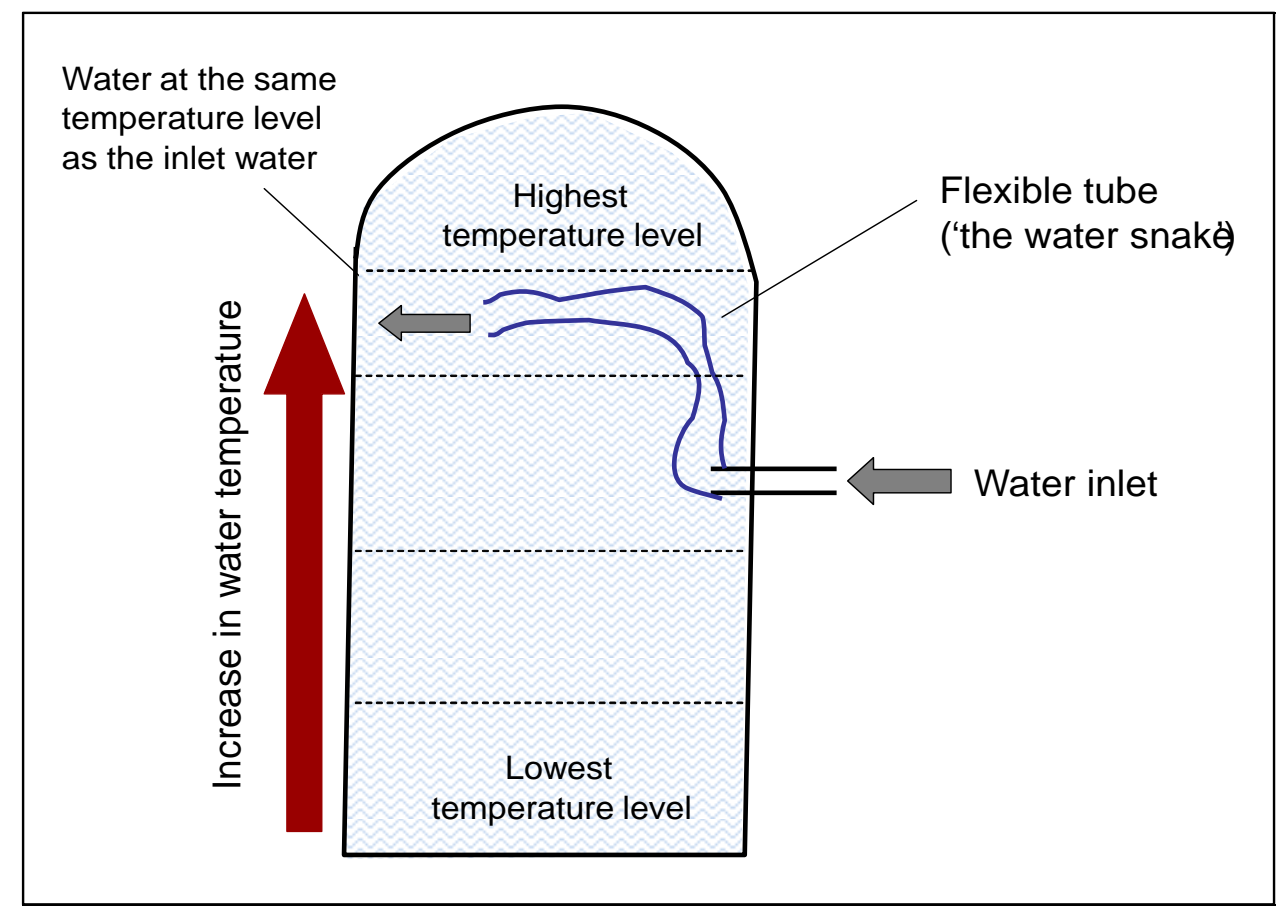

Fig. 1. The simplified schematic diagram of the suggested novel stratified hot water storage tank (the Water Snake). 
A single Water Snake is shown in Fig. 1 for clarity although, typically, there would be several inlets and thus several similar Snakes. A fixed inlet port allows the fluid to flow into the thermal store. The Snake, a flexible sleeve is sealed to the inlet port by means of a seal inside the thermal store. This forces the flow to pass down the Snake to the end which is floating freely within the body of fluid inside the store. The end of the flexible tube will settle in the layer where the densities, and therefore, the temperatures, are the same. Where the snake is passing through layers at different temperatures, it will tend to be vertical. The portion of the snake between the inlet point and the layer at the correct temperature will tend to collapse to the point where drag caused by the flow through the snake balances the pressure difference between the inflow and that in the body of the vessel.

\section{THE EXPERIMENTAL WORK}

First prototype, see Fig. 2, consists of light weight plastic with $80 \mathrm{~mm}$ diameter. A $22 \mathrm{~mm}$ copper tube is used to feed the water into the snake assembly. A simplified test rig was assembled to test the Water Snakes principle. The test rig consisted of an 80 litre clear sided plastic storage tank used as the receiving vessel to demonstrate the Snake, this was connected to a 24 litre plastic storage tank used as a header tank. A copper downpipe was used to transfer water from the header tank to the main test vessel through the prototype water snake. In the down pipe were a quarter turn ball valve used to stop and start the flow and a gate valve used to set the flow rate. During the test, the flow valve remained in the same position such that the flow varied between 700 and 750 Litres / hour. The bottom section of the copper tube was terminated with a right angle bend onto which the prototype flexible tube, the Snake, was attached. This consists of a tube of circumference of about 250 $\mathrm{mm}$ made from a lightweight plastic carrier bag and double sided sticky tape. Where it is joined to the copper tube some additional components are added so that the flow would be calmed as it flowed into the fixed end of the Snake. The end of the Snake had two axial slits cut in it so that the flow from the end could spread out more easily into a horizontal layer. The test was filmed so that the behaviour of the snake could be viewed for analysis.

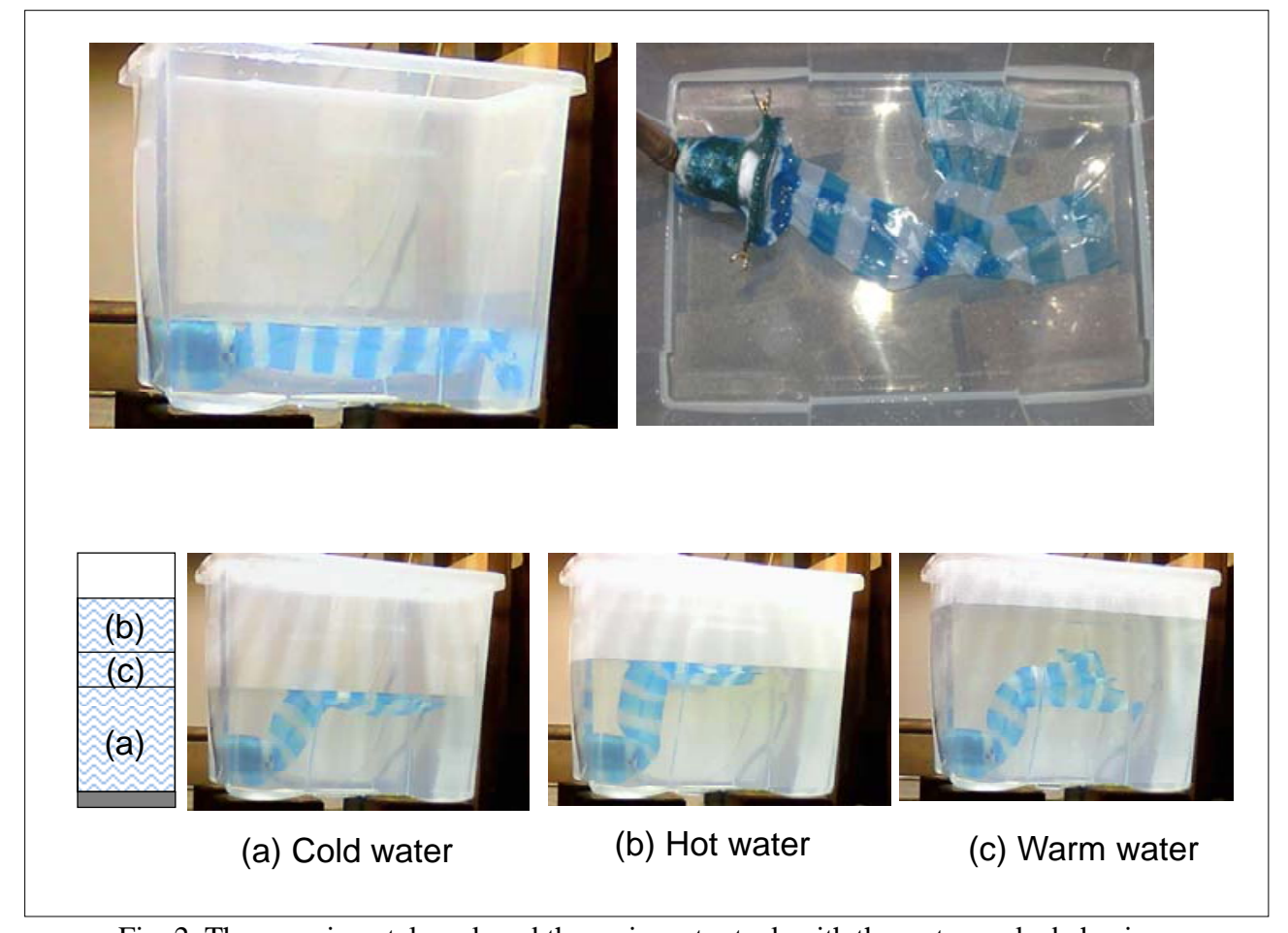

Fig. 2. The experimental work and the main water tank with the water snake behaviour.

\section{RESULTS AND DISCUSSION}

The inlet to the snake was near the bottom of the receiving vessel. The first part of the test consisted of transferring 28 litres of cold $\left(19^{\circ} \mathrm{C}\right)$ water into the bottom of the receiving vessel covering the whole of the snake assembly and allowing any air to be purged from the snake, see Fig. 2-a. After that 26 litres of hot $\left(78^{\circ} \mathrm{C}\right)$ were added causing the snake to lift and allow the hot water to form a layer 
on top, see Fig. 2-b. Finally 22 litres of warm $\left(50^{\circ} \mathrm{C}\right)$ are added, see Fig. 2-c. As expected, the snake moved quickly to deliver a layer of warm at the interface between the hot and cold layers. The result indicated three well defined layers over an overall depth of $375 \mathrm{~mm}$. The images in Fig. 2 indicate the steady state position of the snake during the test. A thermocouple was used to measure the temperatures at $25 \mathrm{~mm}$ intervals from the bottom of the receiving vessel immediately after the three batches of water had been transferred to the receiving vessel. The results are shown in Fig. 3.

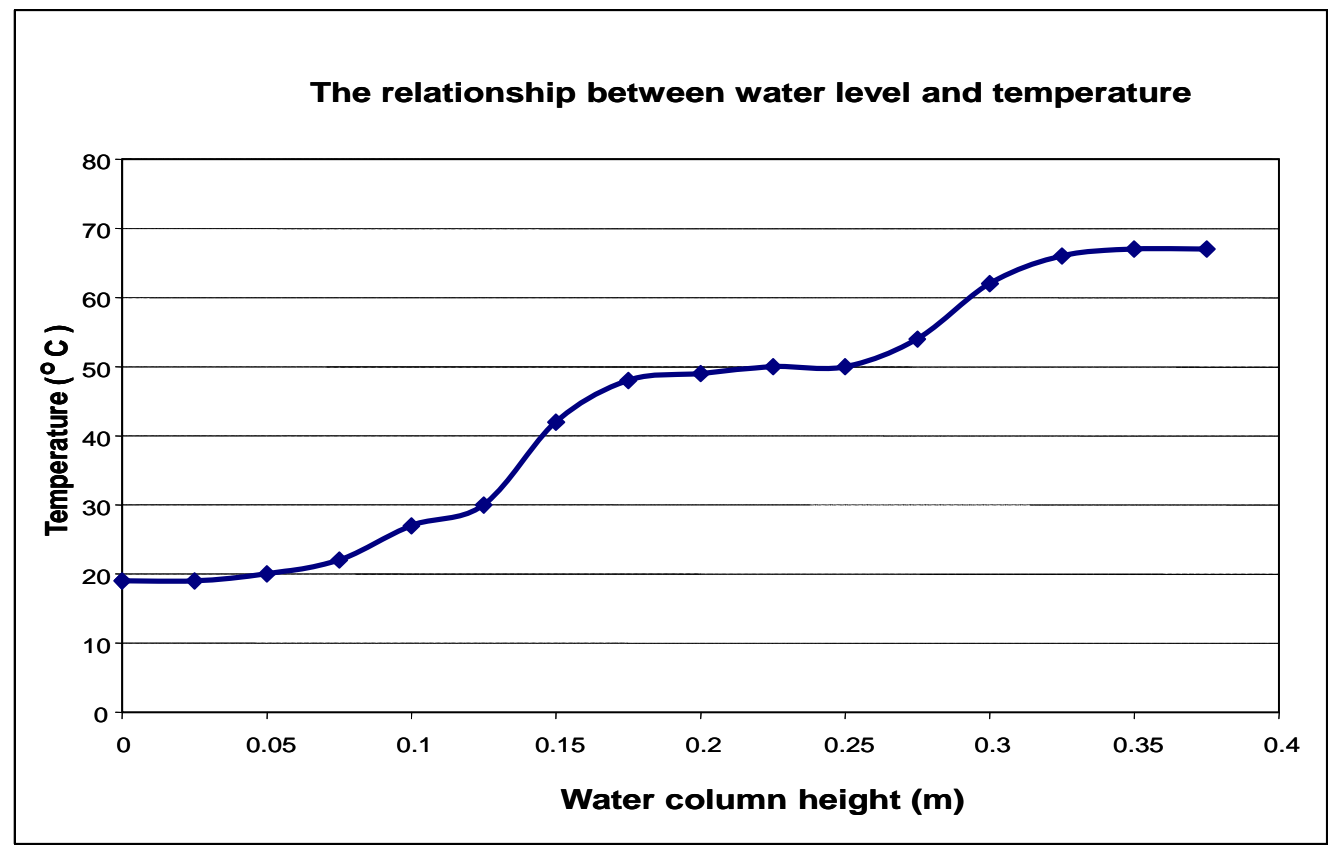

Fig. 3. The relationship between water column height and temperature at the end of the test.

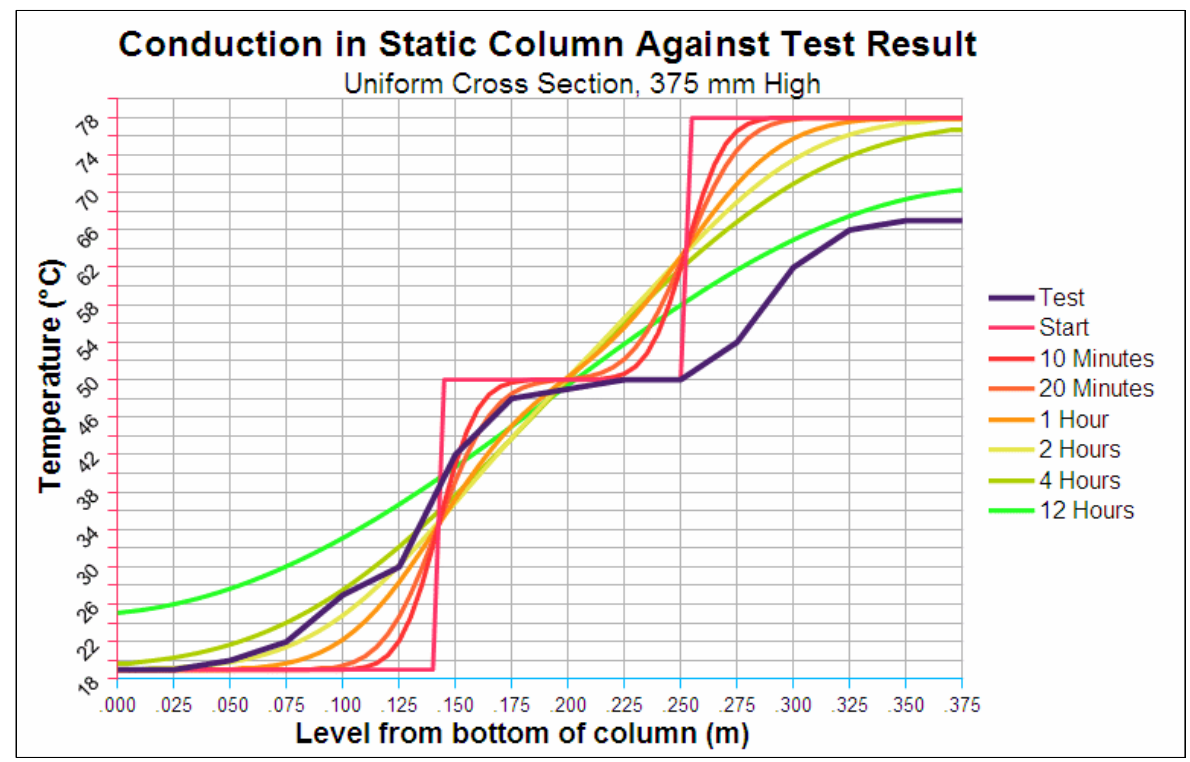

Fig. 4. Theoretical analysis for a stratified hot water tank with a height of 375mm.

Fig. 4 presents the result against a perfect system. The results are represented by the dark line. The lines show the effect of conductivity on the temperature of a column of water starting with three perfect layers in the same proportions and at the same starting temperatures as the test. It also assumes a constant cross section and perfect insulation. 
As can be seen, for lower half of the tank, the test result follows the 2 hour line the most closely. The effect of heat loss by evaporation dropped the temperature of the top layer. The concept of "hours of conduction" could be a useful way of measuring the quality of the stratification in a vessel.
To demonstrate the effectiveness of the water snake based on the test, the model of the thermal gradient change due to conduction was extended to 2 metres as shown in Fig 5 . The 2 hour line has been highlighted as the dark line. This shows what could be achieved using a longer Water Snake in a full size thermal store.

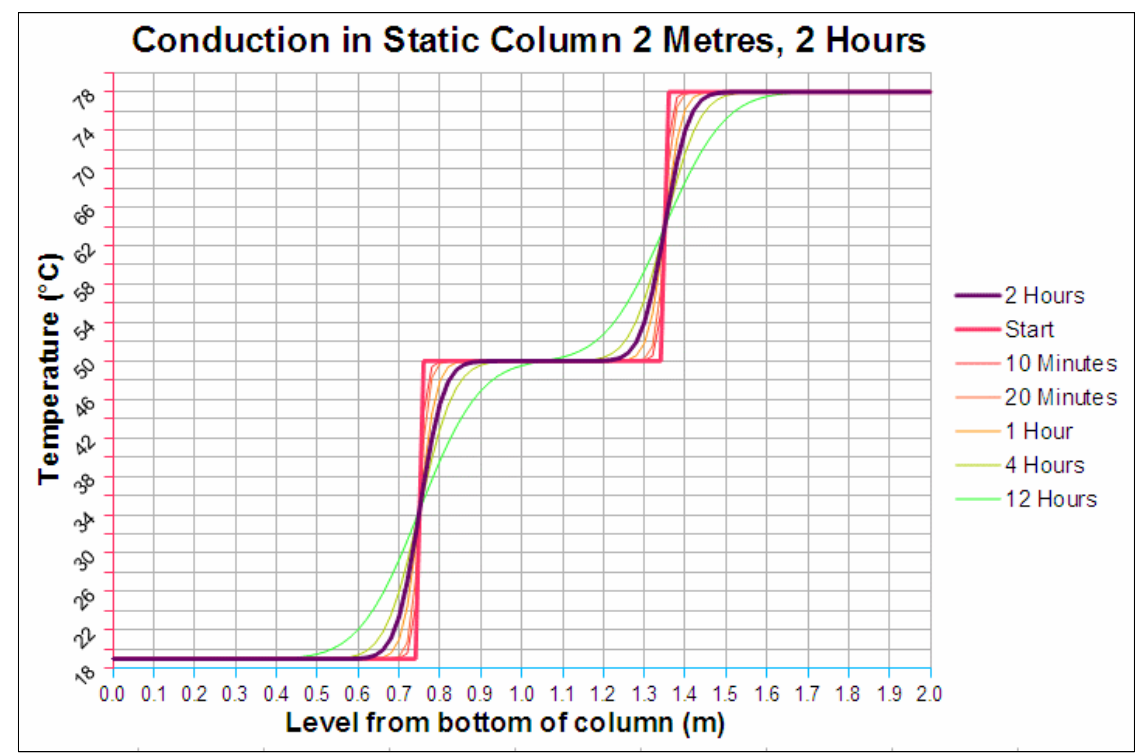

Fig. 5. Theoretical analysis for a stratified hot water tank with a typical height of 2 metres.

\section{DYNAMIC RESPONSE}

Fig. 6 presents the dynamic response of the water snake during the testing of the concept in the stratified hot water storage system. The test has been captured in a novel diagram that represents the introduction of water at different temperature and the response of the water snake. When water at $19{ }^{\circ} \mathrm{C}$ is introduced the snake response keep the end of the snake within the top $3^{\text {rd }}$ of the water volume. When warmer water $\left(78^{\circ} \mathrm{C}\right)$ is introduced (at about time equals 92 seconds), the water snake responds within 3 seconds to the introduction of the warmer water. At time equals 176 seconds, the introduction of water in the middle layer at temperature of $50{ }^{\circ} \mathrm{C}$ allows a response within 6 seconds for the snake to be in the middle correct layer.

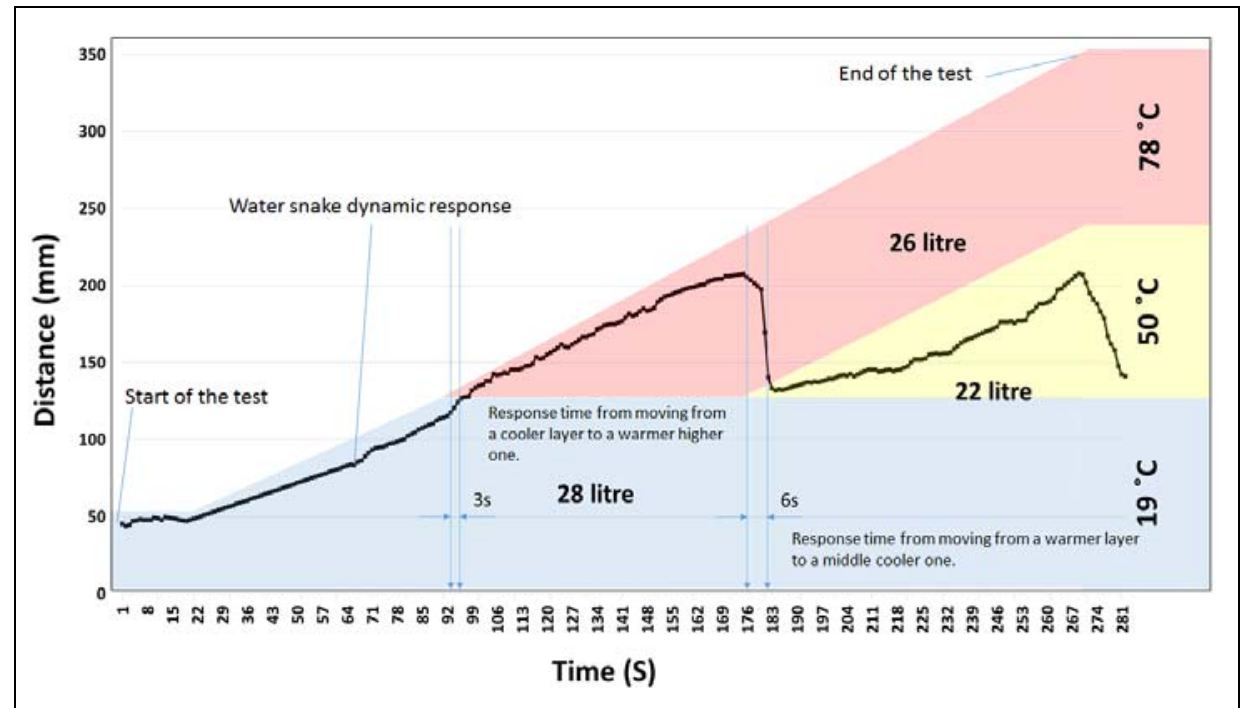

Fig. 6. The dynamic response of the water snake during the testing of the concept in the stratified hot water storage system. 


\section{CONCLUSION}

The benefits of a stratified store have been appreciated for some time. The advent of heat pumps and solar thermal greatly increases the benefits from stratification. It is now entirely realistic for half the calorific value of gas consumed in a power station to appear as electricity entering a building. Air source heat pumps, properly installed, can operate at COPs in excess of 3 giving an immediate advantage over gas fired heating. The COP of a heat pump is directly related to the temperature at which the heat is generated. A good stratified thermal store can significantly increase the average COP of a heat pump. Existing designs for stratified thermal stores rely on fixed baffles, chambers and other features to reduce the turbulence as fluid returns to the store. This means that, inevitably, mixing of fluid at different temperatures will occur and the result is not perfect. A novel approach to design a low cost stratification tanks has been proposed in this paper. A simple and flexible tube, namely the water snake, has been used to generate stratification in a hot water tank. The results of the experimental work and the simulation indicate that the water snake has a significant effect on stratification by reducing turbulence which could significantly reduce the energy consumption and improved efficiency. This system will allow several producers of heat to contribute to the heating system and several consumers to draw from it. Adventitious sources such as solar thermal to be used with the greatest flexibility. It also simplifies the control required as the store just needs to be kept at a minimum temperature as is required to meet the demand. Where some or all of the heat required for a building is produced by electricity it allows heat to be generated at times of high availability, stored and used when required. This has advantages for both the consumer who will see reduced bills and the grid which can reduce peak demand spikes and reduce emissions arising from having to generate inefficiently to cover the requirement. The design is inexpensive, simple and requires no separate control. The method is effective enough to avoid the need to get the fluid in at approximately the right level. This reduces the need for zone valves and controls. Future work will include a comparative study with other existing systems to quantify the benefits to consumers.

\section{REFERENCES}

[1] Michel Y. Haller, Cynthia A. Cruickshank, Wolfgang Streicher, Stephen J. Harrison, Elsa Andersen, Simon Furbon, "Methods to determine stratification efficiency of thermal energy storage processes - Review and theoretical comparison", Solar Energy, Volume 83, Issue 10, October 2009, Pages 1847-1860.

[2] Jinny Rhee, Andrew Campbell, Adele Mariadass, Branden Morhous, "Temperature stratification from thermal diodes in solar hot water storage tank", Solar Energy, Volume 84, Issue 3, March 2010, Pages 507-511.

[3] Michel Y. Haller, Eshagh Yazdanshenas, Elsa Andersen, Chris Bales, Wolfgang Streicher, Simon Furbo, "A method to determine stratification efficiency of thermal energy storage processes independently from storage heat losses”, Solar Energy, Volume 84, Issue 6, June 2010, Pages 9971007.

[4] Y.M. Han, R.Z. Wang*, Y.J. Dai, "Thermal stratification within the water tank", Renewable and Sustainable Energy Reviews 13 (2009) 10141026. 